\title{
Uniaxial and biaxial ratchetting study of SA333 Gr.6 steel at room temperature
}

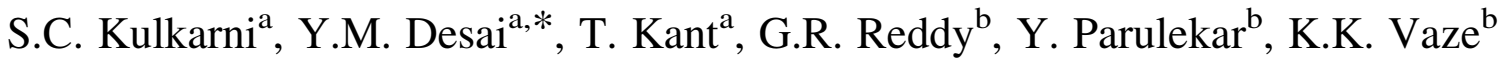 \\ ${ }^{a}$ Department of Civil Engineering, Indian Institute of Technology Bombay, Powai, Mumbai 400 076, India \\ ${ }^{\mathrm{b}}$ Reactor Safety Division, Bhabha Atomic Research Centre, Trombay, Mumbai 400 085, India
}

\begin{abstract}
The phenomenon of ratchetting is defined as constant accumulation of plastic strain or deformation under combined steady state and cyclic loading. It can reduce the fatigue life or can cause failure of piping components or systems subjected to seismic or other cyclic loads. The uniaxial ratchetting characteristics of SA333 Gr.6 steel have been investigated at room temperature in the present paper. The specimens were subjected to cyclic axial stress with a constant mean stress of $200 \mathrm{MPa}$ and a varying amplitude stress of 149, 174, 199 and $224 \mathrm{MPa}$. Tests were also performed on $203.2 \mathrm{~mm}$, Sch 80, SA333 Gr. 6 carbon steel straight pipe. The pipe was subjected to a constant internal pressure of $18 \mathrm{MPa}$ and a cyclic bending load. The effects of amplitude of load on the rate of ratchetting have also been investigated in the present paper. The uniaxial experiments showed that specimens exhibited shakedown at low stress amplitude after some strain accumulation. However, specimens experienced continuous ratchetting at higher stress amplitudes with no shakedown before failure. Ovalization of the pipe crosssection was observed when the pipe was subjected to constant internal pressure and cyclic point load. Local bulging was observed at higher loading. The pipe did not show any shakedown behaviour for the given cycles of loading and exhibited continuous ratchetting under the varying amplitude loading.
\end{abstract}

Keywords: Uniaxial and biaxial ratcheting; Experimental studies; Cyclic loading

\section{Introduction}

Piping networks are often employed in various industrial applications, including nuclear power plants. They play a vital role in proper functioning of a plant. Typically, a piping system consists of straight pipes, curved elbows and tee joints. These elbows and tee joints deform inelastically under the influence of large forces, which could arise due to a large earthquake.

Generally, piping systems in a nuclear power plant are designed for normal operation loads along with cyclic loads, such as earthquake. Cyclic excursions into the plastic range can lead to degradation and failure of such piping due to accumulation of deformation. The strain accumulation induced by cyclic loading is called ratchetting. Ratchetting can be either due to thermal processes or due to mechanical cyclic loading. In the present paper, however, only mechanical ratchetting has been investigated.

Prevention of ratchetting is a difficult problem in the design of a component subjected to cyclic loads that may lead to inelastic deformation. During such loading, material and structural aspects interact. Large deformation of a piping system is possible under combination of primary (constant) and secondary (cyclic) loads. In such a case, a small amount of plastic strain, which is not reversed in each cycle, may lead to unacceptably large accumulated strain. It has been demonstrated experimentally that the cross-section of a circular pipe subjected to cyclic bending ovalizes progressively. Accumulation of ovalization would be at a faster rate at high pressure. Chaboche and Nouailhas [1], Delobelle [2], Delobelle et al. [3], Kang et al. [4,5], Mizuno et al. [6], Ruggles and Krempl [7] and Yoshida [8] have reported experimental results of uniaxial and multiaxial ratchetting for Types 304, 316 and 316L stainless steel. Hassan [9], on the other hand, reported experimental results on a straight pipe 
subjected to internal pressure and cyclic bending load with a four point bending setup. However, a larger experimental database is desirable to understand the ratchetting behaviour of the material more thoroughly and to simulate it more accurately.

The ratchetting response of materials is significantly influenced by the stress history, which depends on the external loads as well as geometry. Behaviours, such as cyclic hardening and cyclic softening significantly influence ratchetting. Effects of factors such as non-proportionality of loading path, variable loading history, etc. on the ratchetting behaviour of the material still need to be revealed by experiments.

The uniaxial ratchetting characteristics of SA 333, Gr. 6 steel at room temperature have been investigated in the present work. Similar studies were also conducted on a straight pipe fabricated from this material. The pipe was subjected to constant pressure and a cyclic bending load. Experimental results have been presented in this paper for both uniaxial as well as biaxial ratchetting. The effect of load amplitude on ratchetting response has also been discussed here.

\section{Material and experimental program}

The material used in the present work for both uniaxial and biaxial ratchetting experiments is SA333 Gr.6 carbon steel. Its chemical composition (by weight) is: C $0.19 \%, \mathrm{Si}$ $0.1 \%$, Mn $0.29-1.06 \%$, P $0.025 \%$, and S $0.025 \%$.

\subsection{Setup for uniaxial cyclic test-uniaxial tensile specimen}

The uniaxial cyclic test specimens had a gauge section of $4.5 \mathrm{~mm}$ diameter and $20 \mathrm{~mm}$ axial length. Tests were conducted in a servo-hydraulic tension-compression testing machine, having $25 \mathrm{kN}$ capacity. The loading process was symmetric stress controlled cycling with a constant mean stress of $200 \mathrm{MPa}\left((2 / 3) \sigma_{y}\right)$ (yield stress $\left.\left(\sigma_{y}\right)=300 \mathrm{MPa}\right)$ and varying amplitude of stress 149, 174, 199 and $224 \mathrm{MPa}$ at different frequency. This constant mean stress of $200 \mathrm{MPa}$ corresponded to a typical pipeline pressure. Strain, displacements and forces were measured at each time step. The yield stress of SA333 Gr.6 was found to be $300 \mathrm{MPa}$ and the ultimate stress was $450 \mathrm{MPa}$. The loading was applied in a cyclic manner starting with the lower stress amplitude $(200+149=349 \mathrm{MPa})$ and was continued until the material stabilised. The stress amplitude was then increased to the next higher value. The test was continued up to $224 \mathrm{MPa}$ of cyclic stress when the specimen failed. The loading history is presented in Fig. 1.

\subsection{Setup for cyclic bending test-straight pipe}

The test involved three-point displacement controlled cyclic bending of straight pipes at constant internal

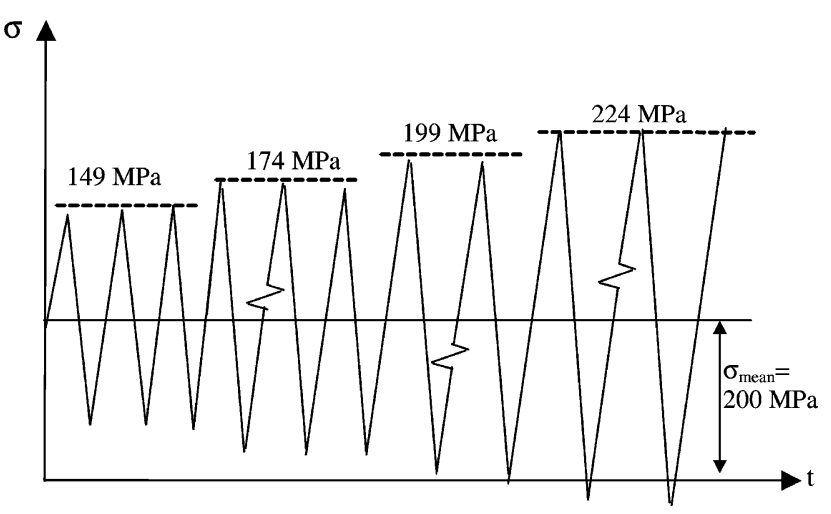

Fig. 1. Load history in cyclic tension test.

pressure. Specimens were of diameter $203.2 \mathrm{~mm}$, schedule 80, SA-333 Gr.6, carbon steel, $3.2 \mathrm{~m}$ long in span. A schematic drawing of the test setup is shown in Fig. 2(a). The pipe was simply supported at the ends and a load was applied with the actuator at the centre. The distance between the two loading points was very small compared to the span of the pipe. The pipe deflected as a rigid body between these two loading points. So, loading was considered to be applied at the centre. The pipe was subjected to a constant internal pressure of $18 \mathrm{MPa}$ and a cyclic bending load. The initial hoop stress $\left(\sigma_{\theta}\right)$ produced in the pipe corresponded to the pressure of $18 \mathrm{MPa}$ (i.e. $\left.\sigma_{\theta}=18 \times 215.85 /(2 \times 12.65)=153.56 \mathrm{MPa}\right)$ where $12.65 \mathrm{~mm}$ is the thickness of the pipe. The pipe was first subjected to 130 cycles of $200 \mathrm{kN}$ load at the centre. This central point load was increased in increments of $20 \mathrm{kN}$ until it reached the maximum cyclic load of $300 \mathrm{kN}$.

Eight post-yield strain gauges were fixed along the length of the pipe to capture ratchetting. A pair of strain gauges was fixed at three locations, viz. (a) at the centre; (b) at a distance $310 \mathrm{~mm}$ from the centre; and (c) at a distance $420 \mathrm{~mm}$ from the centre. A specially made clip gauge was fixed to the pipe along the cyclic loading direction to capture the ovalization effect under combined loading. These clip gauges are shown in Fig. 2(b). It consists of four strain gauges fixed to steel plate, which can record ovalization by averaging the measured strain. In addition, two LVDT (linear variable differential transformer) were fixed perpendicular to the loading direction. Because the distance between the two loads applied at the centre was very small compared to the span of the pipe, a certain amount of rigidity was present at the centre of pipe. Thus the pipe did not bulge at the centre, and bulging occurred at some distance away from the point of application of load. The clip setup and LVDT were fixed at distance $310 \mathrm{~mm}$ from the centre to capture bulging and ovalization under combined loading. Also, one LVDT was fixed at the centre to find the maximum displacement during loading. 


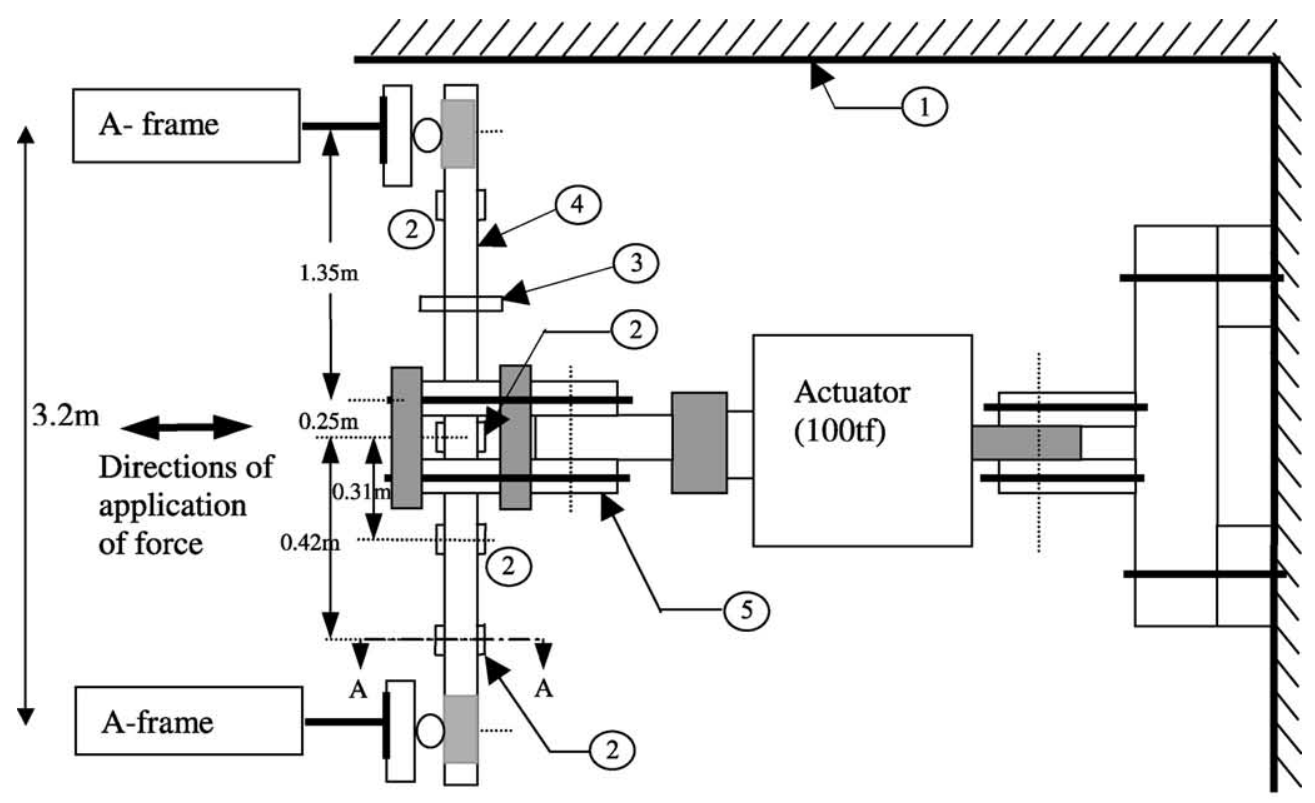

(a)

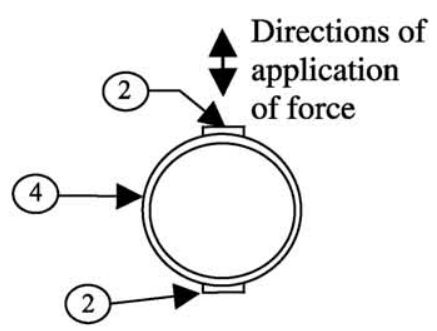

$1=$ Supporting frame

$2=$ Strain gauge (three rosette post yield)

$3=$ Clip gauge

$4=$ Pipe specimen

$5=$ Loading arm

$6=$ Strain gauge (single rosette)

Section A-A

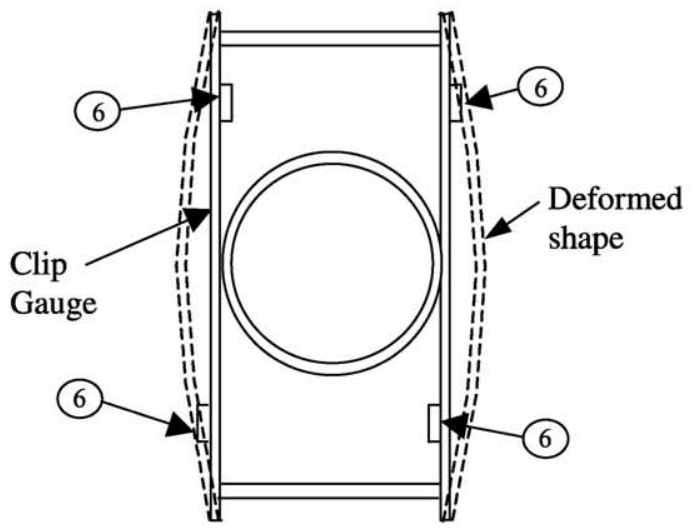

(b)

Fig. 2. (a) Schematic of the three point bend experimental setup used in the biaxial experiment. (b) Details at 3 of clip gauge and deformation under load.

\section{Experimental results}

\subsection{Uniaxial cyclic tests}

The stress-strain curves recorded in the uniaxial ratchetting test are shown in Fig. 3(a and c) at 3 and
$7 \mathrm{~Hz}$, frequency. The strain accumulation with number of cycles is presented in Fig. 4(a and b). The specimen experienced a ratchetting strain initially and then stabilised at maximum stresses of 349, 374 and $399 \mathrm{MPa}$. However, continuous ratchetting was observed with no shakedown at a maximum stress of $424 \mathrm{MPa}$. 
The specimen resisted 51 and 55 (total of about 650 cycles) cycles with stress amplitude $424 \mathrm{MPa}$ at the frequencies of 3 and $7 \mathrm{~Hz}$, respectively, before it failed. The rate of ratchetting was initially high and reduced in subsequent cycles. One of the specimens was directly loaded to a mean stress of $200 \mathrm{MPa}$ in addition to the cyclic load of $224 \mathrm{MPa}$ at $5 \mathrm{~Hz}$ frequency. The specimen

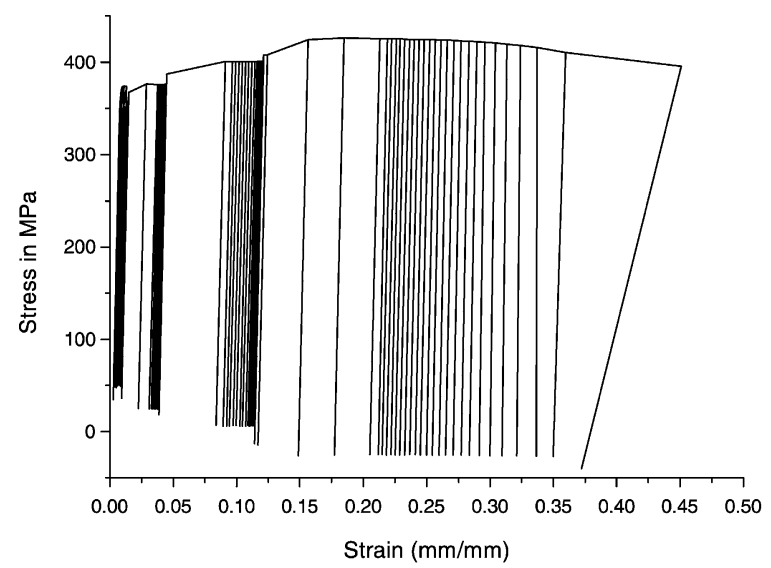

(a) Stress-strain response at $3 \mathrm{~Hz}$ frequency

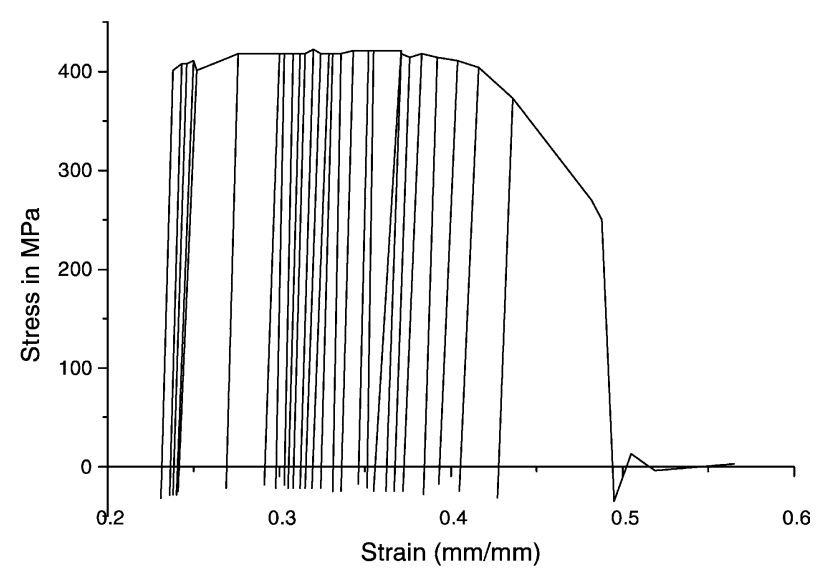

(b) Stress-strain response at $5 \mathrm{~Hz}$ frequency

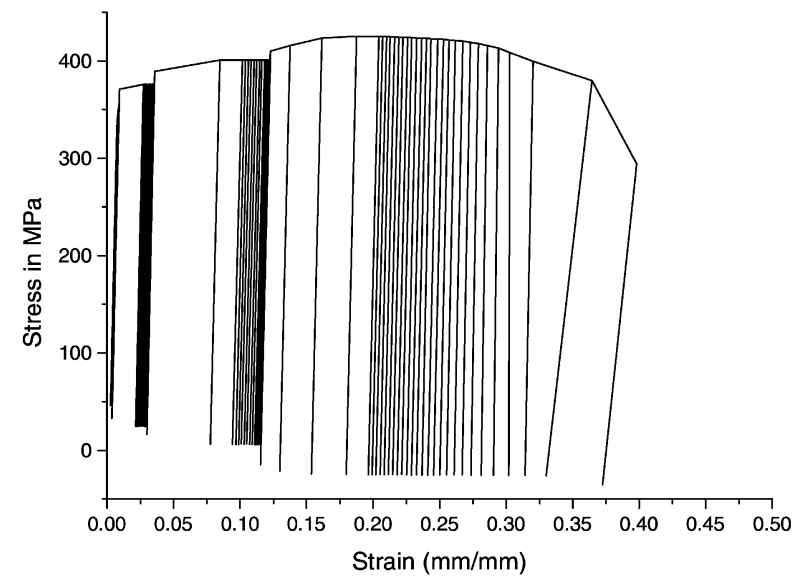

(c) Stress-strain response at $7 \mathrm{~Hz}$ frequency

Fig. 3. Axial strain ratchetting response for uniaxial loading with a constant mean stress. exhibited continuous ratchetting and failed after 34 cycles. The stress-strain response is shown in Fig. 3(b). It can be observed from Fig. 3(a and c) that the stress-strain response remains approximately the same at the frequencies of 3 and $7 \mathrm{~Hz}$. This indicates that the rate of ratchetting is not influenced by the change in frequency. The rate of ratchetting depends on stress amplitude and on the stress history [9].

\subsection{Cyclic bending at constant internal pressure}

The pipe was initially subjected to a constant internal pressure and a monotonic load increasing from 0 to $200 \mathrm{kN}$. The load deflection response is presented in Fig. 5. A finite element code was developed to simulate the monotonic experimental results. Higher order shear deformation shell elements were used to discretise the pipe. On the basis of the overall experimentally observed structural behaviour of this pipe, a half cantilever model was used by applying symmetry condition and correspondingly half the magnitude of point load was applied to get the total results expeditiously without any loss of accuracy. The pipe was

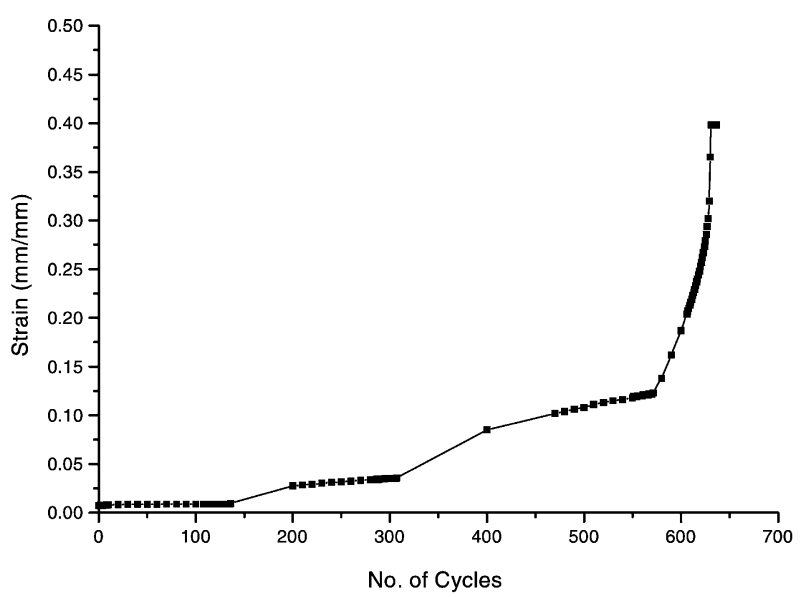

(a) Strain-No. of cycles - $3 \mathrm{~Hz}$ frequency

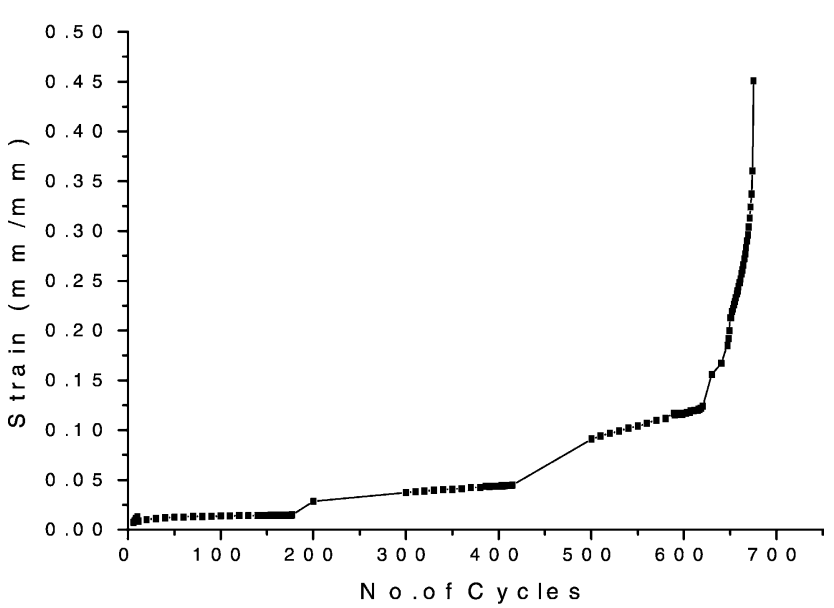

(b) Strain-No. of cycles $-7 \mathrm{~Hz}$ frequency

Fig. 4. Axial strain vs. no. of cycles under uniaxial loading. 
discretised into 56 elements. Such discretization was found to yield a converged solution. The pipe was subjected to a constant pressure of $18 \mathrm{MPa}$ and a point load with magnitude ranging from 0 to $100 \mathrm{kN}$. Large displacement effects were included to capture the non-linear geometric effect of pipe ovalization. Isotropic hardening with the von-Mises yield criterion was used in the inelastic calculations. It can be seen from Fig. 5 that the finite element solution compares well with the experimental data.

The pipe was also subjected to constant internal pressure and cyclic point load for the ratchetting test. The pipe was first subjected to a cyclic bending load of $200 \mathrm{kN}$ for the first few cycles. Because the pipe was also subjected to a constant internal pressure, it was expected that ratchetting would only occur in the circumferential direction with no ratchetting in the longitudinal direction. The strain versus $N$ (number of cycles) relations in both the circumferential and the longitudinal direction are plotted in Fig. 6(a and b). The bending load required to cause inelastic deformation in the pipe is $191.65 \mathrm{kN}$ for the SA 333 steel with yield stress of $300 \mathrm{MPa}$, which is twice the bending load $((W \times 1350 / 43811982.74) \times(203.2 / 2)=$ $300 \rightarrow W=95.826 \mathrm{kN}$ ) calculated for half the pipe. The strain range corresponding to the bending load of $191.65 \mathrm{kN}$ is $\left(\left(300 / 2 \times 10^{5}\right) \times 1 \times 10^{6}\right) \quad 1500 \mu \varepsilon$ and is plotted in Fig. 6(b). The pipe was subjected to the same load for a few more cycles and then the load amplitude was increased to 220, 240, 260 and finally $300 \mathrm{kN}$. It can be seen from Fig. 7 that the ratchetting proceeded without shakedown under the loading conditions in the present work. Hassan [9] also observed a similar trend under fourpoint bending of a pipe with internal pressure and cyclic point loading. The ratchetting is visible in Fig. 7(a) at $200 \mathrm{kN}$ load. The rate of ratchetting under different amplitudes of cyclic bending load can be seen from Fig. 7(b).

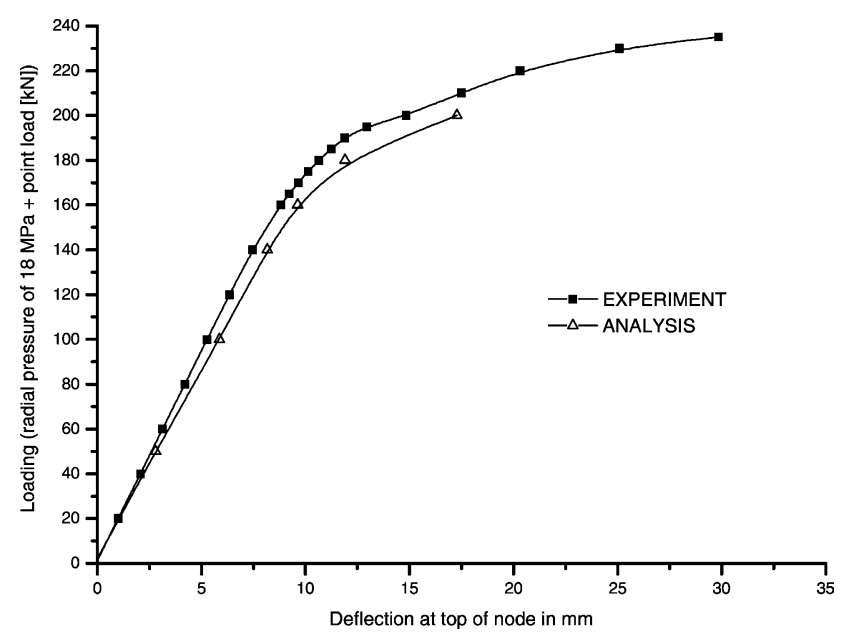

Fig. 5. Comparison of load deflection curve for pipe subjected to constant pressure and gradually increasing monotonic load.

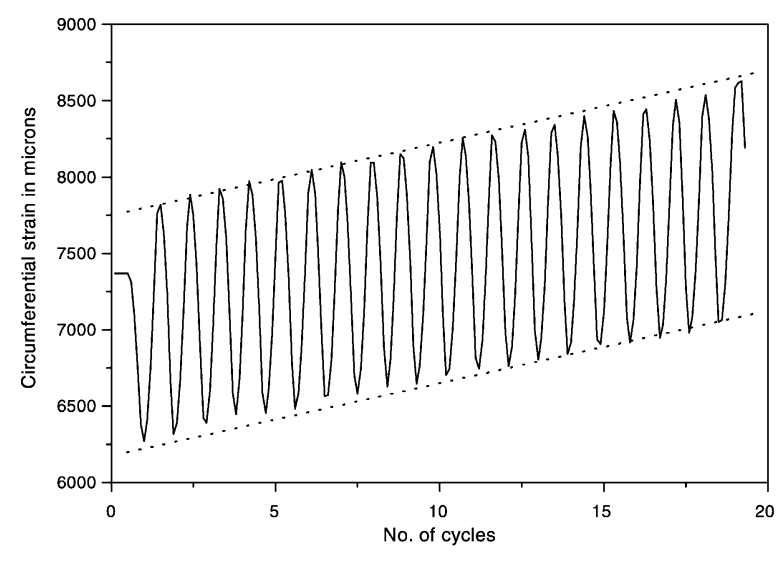

(a)

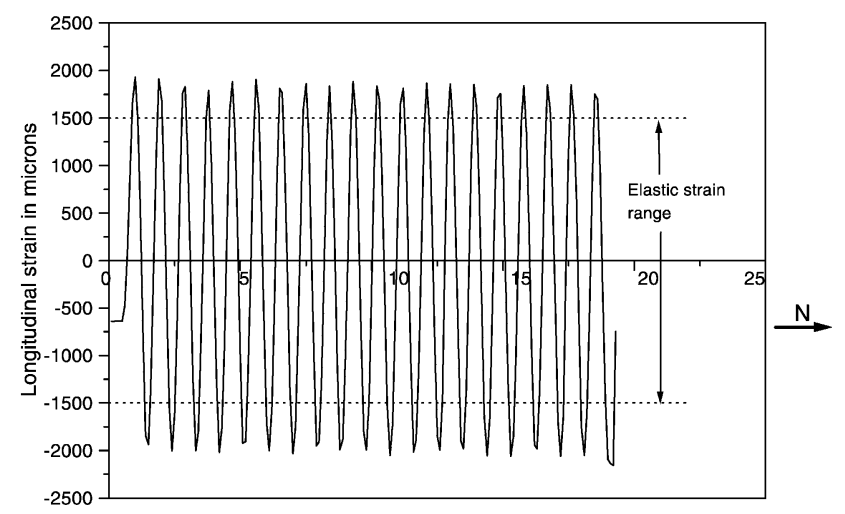

(b)

Fig. 6. Ratchetting response of pipe under constant pressure and cyclic bending load of $200 \mathrm{kN}$. (a) Circumferential direction; (b) longitudinal direction.

\section{Discussion}

Features observed in the uniaxial test and biaxial test are discussed in this section in the context of simulation of ratchetting tests.

At stress amplitudes of 344,374 and $399 \mathrm{MPa}$, the specimen exhibited an initial ratchet under uniaxial loading conditions and subsequently, the material stabilised showing no further ratchetting even as the numbers of cycles were increased. This behaviour is known as shakedown. The rate of ratchetting was initially high at a stress amplitude of $424 \mathrm{MPa}$, reduced subsequently without indication of shakedown and finally the specimen failed. At a lower stress value the specimen exhibited shakedown after some strain accumulation.

It has been observed that frequency has no effect on the rate of ratchetting as indicated by similar stress-strain curves at frequencies of 3 and $7 \mathrm{~Hz}$ in Fig. 3. The specimen showed the same amount of strain accumulation before shakedown at these two frequencies. The amplitude of strain was observed to be about $0.35 \mathrm{~mm} / \mathrm{mm}$ at the $374 \mathrm{MPa}$ stress level at both frequencies. Also, the total strain had an identical value of $0.37 \mathrm{~mm} / \mathrm{mm}$ at the $424 \mathrm{MPa}$ stress level 


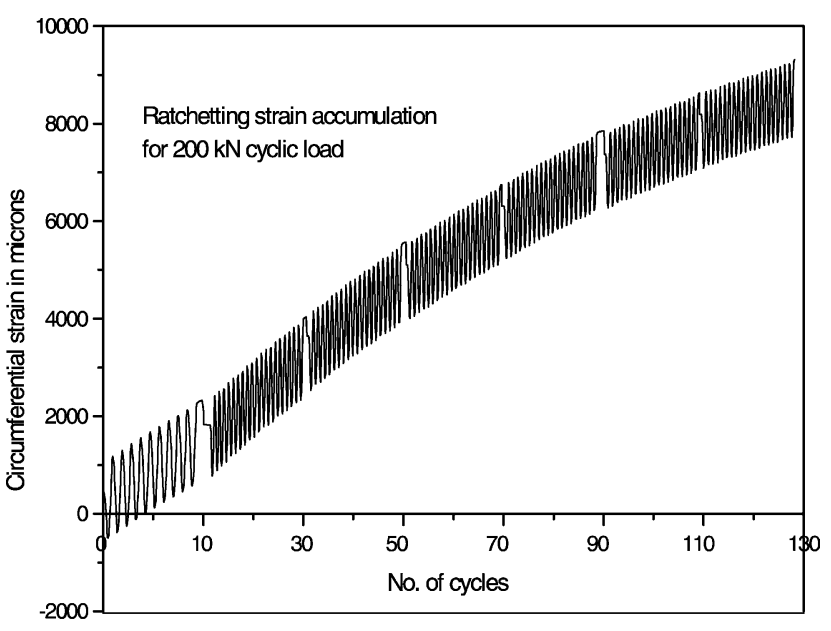

(a)

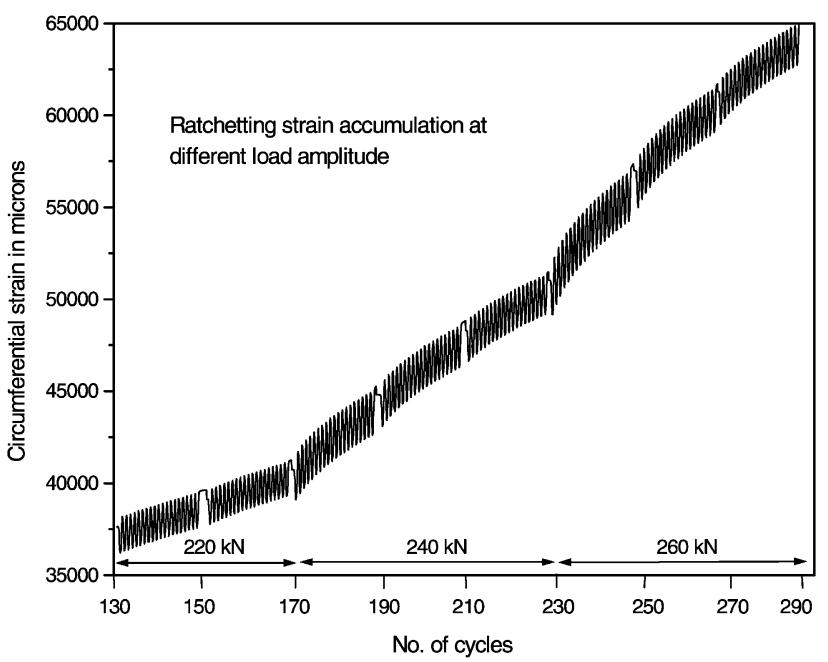

(b)

Fig. 7. Ratchetting response of pipe; (a) $200 \mathrm{kN}$ of cyclic load with 130 cycles; (b) cyclic load with varying amplitude of 220, 240 and $260 \mathrm{kN}$.

for 3 and $7 \mathrm{~Hz}$ frequencies. This range covers typical earthquake excitation frequencies. The rate of ratchetting appears to depend only on stress amplitude and stress history within this range of frequencies. Frequency effects outside this range may well affect the stress-strain behaviour of the material and therefore the ratchetting behaviour.

As the pipe was subjected to internal pressure along with cyclic loading under biaxial testing, no ratchetting took place in the longitudinal direction and the ratchetting was observed only in the circumferential direction during the entire loading history.

The strain accumulation was large at the centre of the pipe and reduced substantially towards the ends. The strain gauge fixed at the end of pipe showed no strain accumulation and no ratchetting in the circumferential direction at the $200 \mathrm{kN}$ bending load. However, the pipe started to ratchet subsequently at higher loads.

The circumferential ratchetting strain, $\varepsilon_{\theta}$, was found to increase progressively. However, the rate $\mathrm{d} \varepsilon_{\theta} / \mathrm{d} N$ decreased

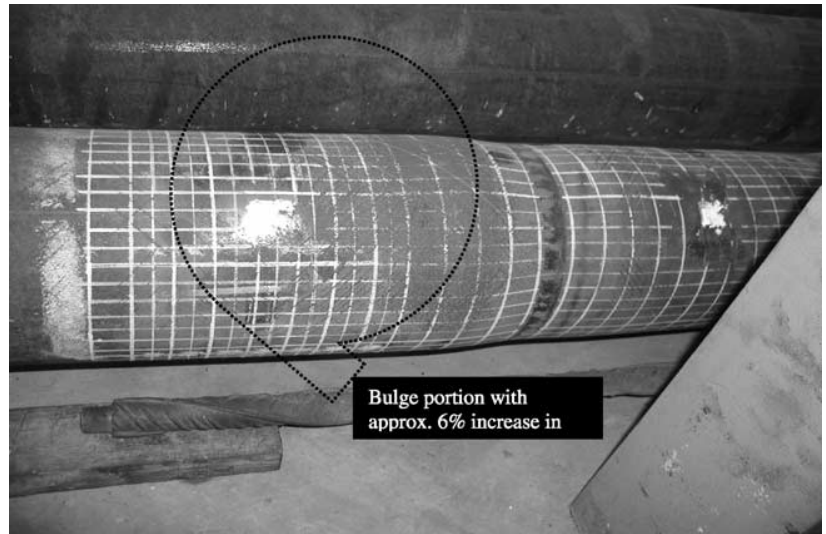

Fig. 8. The final deformed shape of the pipe under cyclic load of $300 \mathrm{kN}$ and constant pressure of $18 \mathrm{MPa}$.

with the number of stress cycles $N$. When the load amplitude was increased, the ratchetting strain $\varepsilon_{\theta}$ and the rate $\mathrm{d} \varepsilon_{\theta} / \mathrm{d} N$ also increased correspondingly as shown in Fig. 7(b). The rate of ratchetting was linear initially and then became non-linear as shown in Fig. 7(a). The clip gauge showed significant ovalization of the pipe during loading.

The rate of ratchetting was found to depend significantly on the load amplitude. The rate of ratchetting was higher at higher load amplitude as shown in Fig. 7. Further, the strain accumulation/cycle was approximately $210.502 \mu \mathrm{m} /$ cycle at the load of $260 \mathrm{kN}$ as compared to $60.00 \mu \mathrm{m} /$ cycle at $200 \mathrm{kN}$ load.

The pipe exhibited significant plastic deformation at the $300 \mathrm{kN}$ load. Also, ovalization of the pipe was observed with local buckling and the pipe was on the verge of failure. The deformed shape of the pipe with ovalization is shown in Fig. 8. The diameter of the pipe increased by about $6 \%$ with respect to the original diameter.

\section{Conclusions}

The uniaxial and biaxial ratchetting characteristics of SA333 Gr.6 steel at room temperature were investigated experimentally. Specimens were subjected to constant mean stress of $200 \mathrm{MPa}$ and cyclic axial stress of 144, 174, 199 and $224 \mathrm{MPa}$ under uniaxial conditions.

Similar tests were carried on a pipe for biaxial ratchetting. The pipe having $203.2 \mathrm{~mm}$ (8 in.) diameter was subjected to constant internal pressure of $18 \mathrm{MPa}$ and a cyclic bending load. The main result from both tests can be summarized as follows.

1. The uniaxial ratchetting of the material was found to depend strongly on the value of the mean stress, stress amplitude and on their histories. The ratchetting strain and its rate were observed to increase with increasing stress levels. 
2. The specimens exhibited shakedown under uniaxial conditions after some strain accumulation at lower stress amplitudes. However, the specimens showed continuous ratchetting with no shakedown and eventually failed at higher stress amplitude (424 MPa).

3. A change in frequency from 3 to $7 \mathrm{~Hz}$ seemed to have no effect on the rate of ratchetting, which was found to depend only on the stress amplitude and the stress history.

4. On the basis of experiments, it appears that ratchetting would occur in the circumferential direction for a pipe subjected to constant internal pressure and cyclic bending load with no ratchetting observed in longitudinal direction.

5. The biaxial ratchetting of SA333 Gr.6 was found to depend on the load amplitude. The rate of ratchetting was higher at high load levels. However, the ratchetting rate $\mathrm{d} \varepsilon_{\theta} / \mathrm{d} N$ decreased with the number of stress cycles $N$. A continuous ratchetting was observed with no shakedown effect in the present experiment for the given loading cycles.

6. The pipe experienced significant ovalization and bulging during the loading process. This cross-sectional distortion would be an important factor for final failure of the pipe.

\section{Acknowledgements}

The work presented here has been sponsored by Board of Research in Nuclear Sciences (BRNS Grant No. 99KA012). The authors are grateful to Dr J.K. Chakravarthy and $\mathrm{Mr}$ C. Gupta, Mr J.S. Dubey, MSD, BARC for their technical support in performing the experiments on uniaxial tensile specimens. The authors acknowledged with thanks help rendered by $\mathrm{Mr}$ M.A. Khan and $\mathrm{Mr}$ S.N. Bodele and $\mathrm{Mr}$ K.K. Bavu, BARC in conducting the biaxial pipe test. Also, invaluable discussions and suggestions by Shri H.S. Khushwa (BARC) and Dr M.S. Sivakumar (IIT, Madras) are gratefully acknowledged. Constructive comments of reviewers are also acknowledged.

\section{References}

[1] Chaboche JL, Nouailhas D. Constitutive modeling of ratchetting effects. Part I. Experimental facts and properties of classical models. ASME J Engng Mater Technol 1989;111:384-92.

[2] Delobelle P. Synthesis of the elastoviscoplastic behaviour and modelization of an austenitic stainless steel over a large temperature range under uniaxial and biaxial loading. Int J Plast 1993;9:65-85.

[3] Delobelle P, Robinet P, Bocher L. Experimental study of phenomenological modelization of ratchet under uniaxial and biaxial loading on an austenitic stainless steel. Int J Plast 1995;11:295-330.

[4] Kang GZ, Gao Q, Yang XJ, Sun YF. An experimental study on uniaxial and multiaxial strain cyclic characteristics and ratchetting of $316 \mathrm{~L}$ stainless steel. J Mater Sci Technol 2001;17:210-23.

[5] Kang G, Qing G, Cai L, Sun Y. Experimental study on uniaxial and nonproportionally multiaxial ratchetting of SS304 stainless steel at room and high temperatures. Nucl Engng Design 2002;216:13-26.

[6] Mizuno M, Mima Y, Abdel-Karim M, Ohno N. Uniaxial ratchetting of 316FR steel at room temperature. I. Experiments. ASME J Engng Mater Technol 2000;122:29-34.

[7] Ruggles MB, Krempl E. The influence of test temperature on the ratchetting behaviour of Type 304 stainless steel. ASME J Engng Mater Technol 1989;111:378-83.

[8] Yoshida F. Uniaxial and biaxial creep-ratchetting behaviour of SUS304 stainless steel at room temperature. Int J Pressure Vessels Piping 1990; 44:207-23.

[9] Hassan T, Zhu Y, Matzen V. Improved ratchetting analysis of piping components. Int J Pressure Vessels Piping 1998;75:643-52. 